\title{
Computational Assessment and Pharmacological Property Breakdown of Eight Patented and Candidate Drugs against Four Intended Targets in Alzheimer's Disease
}

\author{
Bishajit Sarkar ${ }^{1}$, Syed Sajidul Islam ${ }^{1}$, Md. Asad Ullah1, Sohana Hossain"1, \\ Md. Nazmul Islam Prottoy ${ }^{1}$, Yusha Araf ${ }^{2}$, Masuma Afrin Taniya ${ }^{3}$ \\ ${ }^{1}$ Department of Biotechnology and Genetic Engineering, Faculty of Biological Sciences, Jahangirnagar University, Savar, Dhaka, \\ Bangladesh \\ ${ }^{2}$ Department of Genetic Engineering and Biotechnology, Faculty of Life Sciences, Shahjahal University of Science and Technology, \\ Sylhet, Bangladesh \\ ${ }^{3}$ Department of Microbiology, School of Life Sciences, Independent University Bangladesh, Dhaka, Bangladesh \\ Email: *sarkarbishajit@gmail.com
}

How to cite this paper: Sarkar, B., Islam, S.S., Ullah, M.A., Hossain, S., Prottoy, M.N.I., Araf, Y. and Taniya, M.A. (2019) Computational Assessment and Pharmacological Property Breakdown of Eight Patented and Candidate Drugs against Four Intended Targets in Alzheimer's Disease. Advances in Bioscience and Biotechnology, 10, 405-430.

https://doi.org/10.4236/abb.2019.1011030

Received: August 27, 2019

Accepted: November 22, 2019

Published: November 25, 2019

Copyright ( 2019 by author(s) and Scientific Research Publishing Inc. This work is licensed under the Creative Commons Attribution International License (CC BY 4.0).

http://creativecommons.org/licenses/by/4.0/

\section{c) (i) Open Access}

\begin{abstract}
Alzheimer's Disease $(\mathrm{AD})$ is the most prevalent age-related dementia. AD can be caused by abnormal processing of amyloid precursor protein (APP) or by oxidative stress or may be due to the actions of kinases or the degeneration and loss of functions of neurons in the brain. Although various treatments have already gained success in the in vitro studies, however, till now not a single satisfactory drug has been proven that can cure this disease permanently till now. In this study, the best possible drug has been determined from a group of drug molecules using methods of molecular docking. Molecular docking is a computational approach which helps to determine the best molecule from a group of molecules which may bind with the highest affinity with the intended target by mimicking the original biological environment in a computer. The tested drug molecules in this experiment are the disease modifying agents, capable of inhibiting a particular protein involving in the $\mathrm{AD}$ pathway. Eight drug molecules (ligands)-memantine $(-4.075 \mathrm{Kcal} / \mathrm{mol})$, hymenialdisine $(-8.079 \mathrm{Kcal} / \mathrm{mol})$, tideglusib $(-6.445 \mathrm{Kcal} / \mathrm{mol})$, kenpaullone $(-7.545 \mathrm{Kcal} / \mathrm{mol})$, dihydrospiro[dibenzo[a,d][7]annulene-5,4'-imidazol] $(-4.742 \mathrm{Kcal} / \mathrm{mol})$, harmine $(-7.57 \mathrm{Kcal} / \mathrm{mol})$, harmol $(-6.583 \mathrm{Kcal} / \mathrm{mol})$ and 1-Methyl-4-Phenylpyridinium $(-5.214 \mathrm{Kcal} / \mathrm{mol})$, have been docked successfully against four targets (proteins)-N-Methyl-D-Aspartate Receptor (NMDAR), glycogen synthase kinase- $3 \beta$ (GSK-3 $\beta$ ), beta-secretase ( $\beta$-secretase) and dual specificity tyrosine $(\mathrm{Y})$-phosphorylation-regulated kinase $1 \mathrm{~A}(\mathrm{DYR}-\mathrm{K} 1 \mathrm{~A})$ in
\end{abstract}


this experiment which are intended targets in current AD treatment approaches. Investigation of docking results, druglikeness properties and $\mathrm{ADME} / \mathrm{T}$ testing results suggest that the best findings of this experiment are memantine, hymenialdisine, dihydrospiro[dibenzo[a,d][7] annulene-5,4'-imidazol] and harmol, that could be the best possible drugs for the treatment of $\mathrm{AD}$.

\section{Keywords}

Alzheimer's Disease, Harmol, $\beta$-Secretase, Docking, Tau Protein, $\beta$-Amyloid

\section{Introduction}

Alois Alzheimer first described Alzheimer's Disease (AD) in 1907. It is the most prevalent age-related dementia in the world [1]. $\mathrm{AD}$ is a common type of age-related dementia that is increasing its numbers day by day [2]. The common symptoms of $\mathrm{AD}$ include functional and intellectual morbidity, hallucinations, delusions, psychomotor dysregulation etc. [3]. Genetic causes are also involved in the familial cases of $\mathrm{AD}$ [4]. However, there are many reasons that lead to the onset of AD development. Many hypotheses shed light on several reasons. One such hypothesis is the "amyloid cascade hypothesis". According to this hypothesis, the deposition of $\beta$-amyloid plaques in the brain is the main reason of $\mathrm{AD}$ development. These plaques are generated by abnormal processing of amyloid precursor protein (APP) by $\beta$-secretase enzyme. These plaques interfere with the normal activities and functions of the brain [5]. Moreover, there is another hypothesis called "oxidative stress hypothesis". According to this hypothesis, increased amount of iron and mercury in the brain is capable of generating free radicals, thus increasing lipid peroxidation and protein and DNA oxidation in the brain and thus producing stresses on the brain. And these stresses produced by oxidation in the brain are mainly responsible for $\mathrm{AD}$ development [6]. According to another hypothesis called "cholinergic hypothesis", the degeneration and loss of functions of cholinergic neurons and cholinergic neurotransmission in the brain, cause $\mathrm{AD}$ [7]. Although there is no permanent treatment to cure $\mathrm{AD}$, scientists are working on various disease modifying approaches that target various enzymes that take part in the regulatory pathways which may lead to the onset of $\mathrm{AD}[8]$.

Various compounds can be used as disease modifying agents to treat $\mathrm{AD}$. The main concept of disease modifying treatment is to modify the protein or enzymes involved in the AD pathway. Most of such modifying agents are not commercially available yet. Memantine can be used to treat abnormal N-methylD-aspartate (NMDA) pathway by inhibiting the NMDA receptors (NMDARs) [9]. Hymenialdisine, tideglusib and kenpaullone have gained success in inhibiting glycogen synthase kinase-3 $\beta$, a major enzyme involved in $\mathrm{AD}$ [10] [11] [12]. Dihydrospiro[dibenzo[a,d][7]annulene-5,4'-imidazol] has been tested for its 
$\beta$-secretase inhibiting property [13]. Moreover, there is evidence that, one of the kinases involved in tau protein phosphorylation, dual specificity tyrosine (Y)-phosphorylation-regulated kinase 1A (DYRK1A) is inhibited by harmine, harmol and 1-methyl-4-phenylpyridinium [14].

In this study, we have conducted experiments to determine which one of the above mentioned ligand molecules could be the best option to treat $\mathrm{AD}$ by interfering specified target proteins involved in the AD pathway.

\subsection{N-Methyl-D-Aspartate Receptor (NMDAR) (Receptor) and Memantine (Ligand)}

In the mammalian central nervous system (CNS), a potential neurotransmitter, glutamate plays very important roles and it is the main excitatory neurotransmitter in the CNS. Glutamate mediates its effects by many families of receptors such as ionotropic glutamate receptors (iGluRs) and metabotrophic glutamate receptors (mGluRs). The iGluRs family contains many types of receptors. Among them, N-methyl-D-aspartate receptors or NMDARs are the receptors that are mainly responsible for learning and memory [15]. Therefore, any disruption in the normal signalling pathway of the NMDARs may lead to the damage of the CNS that may cause the AD to develop.

$\mathrm{N}$-methyl-D-aspartate (NMDA) selectively mediates NMDARs. The NMDARs are encoded by human genes GRIN1, GRIN2A, GRIN2B, GRIN2C and GRIN2D [16]. The NMDARs can be divided into two groups: synaptic and extrasynaptic NMDARs. The activation of synaptic NMDARs leads to synaptic plasticity and cell survival (Figure 1) [17]. However, inappropriate NMDAR signalling leads to injuries in the neuronal system.

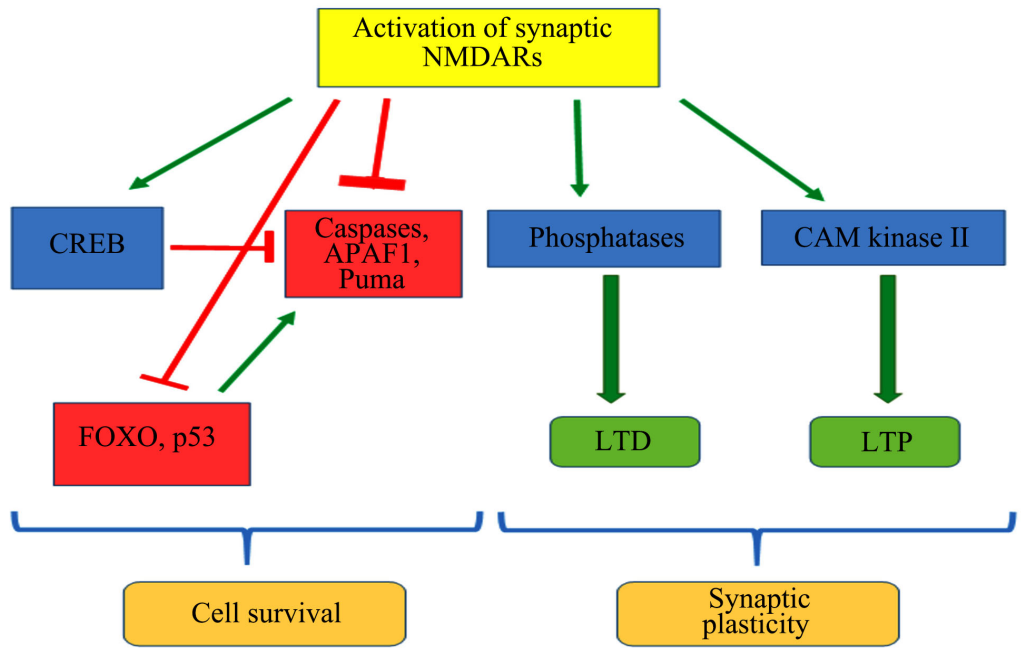

Figure 1. NMDAR signalling pathways. Activated synaptic NMDARs activate CAM Kinase II and Phosphatases that mediate synaptic plasticity by inducing long-term potentiation (LTP) and long-term depression (LTD). Activated synaptic NMDARs mediate cell survival by activating survival transcription factor CREB and inhibiting death transcription factors (FOXO/p53) and death signals (Caspases, APAF1 and Puma) [17]. 
In normal condition, upon secretion, glutamate is secreted and binds to NMDAR, thus activates the receptor and mediates the calcium ion transport across the neuron cell. However, during abnormal signalling, inappropriate activation of NMDARs occurs. This causes excessive entry of $\mathrm{Na}^{+}$and $\mathrm{Cl}^{-}$ions into the neuron cells, which is responsible for acute neuronal swelling. Moreover, the excessive entry of $\mathrm{Ca}^{2+}$ ions into the post-synaptic neurons causes delayed neuronal degeneration (Figure 2) [18]. Therefore, the entry of excessive levels of ions leads to the toxic condition in the cell and causes neuronal cell death. This leads to the onset of $\mathrm{AD}$. On the other hand, the $\beta$ amyloid plaques, formed due to AD, selectively activates extrasynaptic NMDARs. The extrasynaptic NMDARs cause the deleterious effects like tau protein phosphorylation and induction of apoptosis by activating caspase-3, which also leads to the onset of $\mathrm{AD}$ [19].

Administration of memantine can block the activity of NMDARs by binding with those receptors and thus mediate its therapeutic properties in inhibition of $\mathrm{AD}$ [20]. In this experiment, memantine (PubChem CID: 4054) was used to dock against GluN2D (PDB ID: 3OEM), which is a NMDAR or ionotropic glutamate receptor [21].
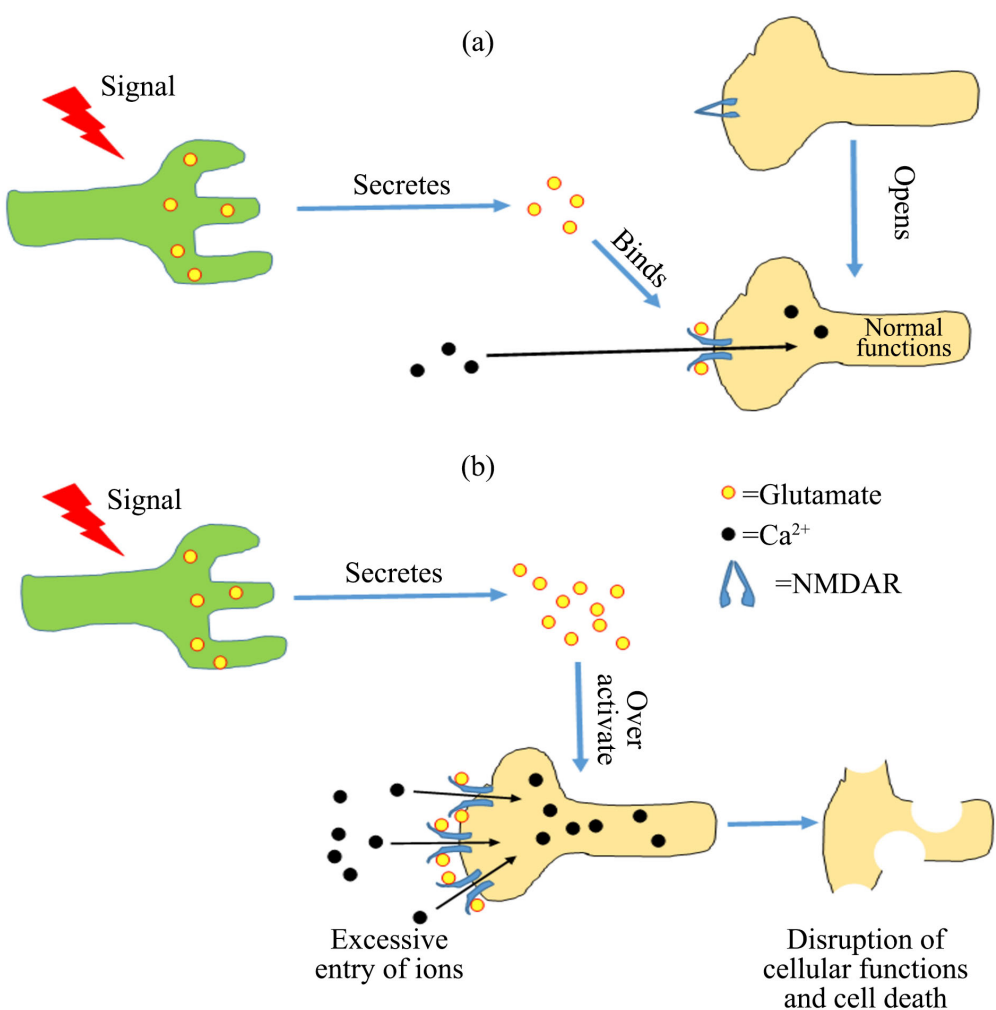

Figure 2. Figure showing the role of glutamate in AD. In normal condition (a), the glutamate is secreted and binds to NMDAR, thus activates the receptor and mediates the calcium ion transport across the neuron cell. In abnormal condition (b), inappropriate stimulation of glutamate production causes the over-activation of NMDARs, which causes excessive entry of ions into the neuron cells, causing the disruption of cellular functions. 


\subsection{Glycogen Synthase Kinase-3 $\beta$ (Receptor) and Hymenialdisine, Tideglusib and Kenpaullone (Ligands)}

Glycogen synthase kinase-3 $\beta$ (GSK-3 $\beta$ ) is an enzyme kinase that plays important role in the development of $\mathrm{AD}$ by phosphorylating the tau protein [22]. $\mathrm{A} \beta$ is caused by defective proteolytic processing of amyloid precursor protein (APP). This defection leads to the production and deposition of 42 amino acids long neurotoxic forms of $\beta$-amyloid (A $\beta$ ) peptides. Three enzymes determine whether the neurotoxic forms of $\beta$-amyloid will be formed or not. $\beta$-secretase and $\gamma$-secretase cleave APP sequentially at the $\mathrm{N}$-terminus and C-terminus, respectively. These cleavages lead to the beta amyloid production and when $\alpha$-secretase cleaves APP, the possibility of formation of A $\beta$ minimizes [23] [24] [25]. APP is a surface membrane protein that can be processed by two major pathways: non-amyloidogenic pathway and amyloidogenic pathway. In the non-amyloidogenic pathway, the $\alpha$-secretase and $\gamma$-secretase enzymes cleave the transmembrane domain of APP, sequentially. These cleavages give rise to the fragments that are easily degradable [26]. However, in amyloidogenic pathway, the APP is cut by $\beta$-secretase and $\gamma$-secretase, which form $\beta$-amyloid (A $\beta$ ) peptides and the $\mathrm{A} \beta$ peptides tend to aggregate and form plaques [27]. Microtubule associated protein (MAP) tau is a protein that is found in the neuron cells and their main function is to stabilize the microtubules. They are phosphorylated in lesser extent in the normal adult brain. However, in the AD patients, they are found to be highly phosphorylated. The abnormally phosphorylated tau acquires the shape of paired helical filaments (PHFs) and forms neuro fibrillary tangles (NFTs) with other abnormally phosphorylated tau proteins. These NFTs are insoluble tangles that appear to be accumulated as tangled mass in the brain. NFTs interfere with the normal functions of the neurons by destabilizing the microtubules [28]. One of the proteins responsible for the tau phosphorylation is GSK-3 $\beta$. The GSK-3 is a serine/threonine kinase enzyme. In the brain, the GSK- $3 \beta$ is responsible for the tau phosphorylation [29]. GSK- $3 \beta$ phosphorylates 36 sites on the tau protein [30]. There is evidence that, $\mathrm{A} \beta$ is responsible for the tau phosphorylation [31]. A $\beta$ activates and causes over production of GSK-3 $\beta$ signaling by inhibiting the inhibitory phosphorylation mechanism of this enzyme. Therefore, the formation of $\mathrm{A} \beta$ directly causes the over-activation of GSK-3 which in turn hyper-phosphorylate the tau protein and form NFTs. NFTs ultimately result the $\mathrm{AD}$ development. Moreover, the formation of NFTs later leads to the apoptosis of the neuron (Figure 3) [32]. A potent inhibitor of GSK- $3 \beta$ is hymenialdisine [10]. Studies have found that another compound named tideglusib can also be used as GSK-3 $\beta$ inhibitor [11]. Moreover, kenpaullone is another compound that has GSK- $3 \beta$ inhibitory activity [12]. Molecular docking has already been performed successfully against the GSK- $3 \beta$ (PDB ID: 1Q5K) using 1,3-disubstituted-1H-pyrazol-5-ols as ligands [33]. In the experiment, docking was performed using hymenialdisine (PubChem CID: 11313622), tideglusib (PubChem CID: 135413546) and kenpaullone (PubChem CID: 3820 ) as ligands against the GSK-3 $\beta$ (PDB CID: 1Q5K). 


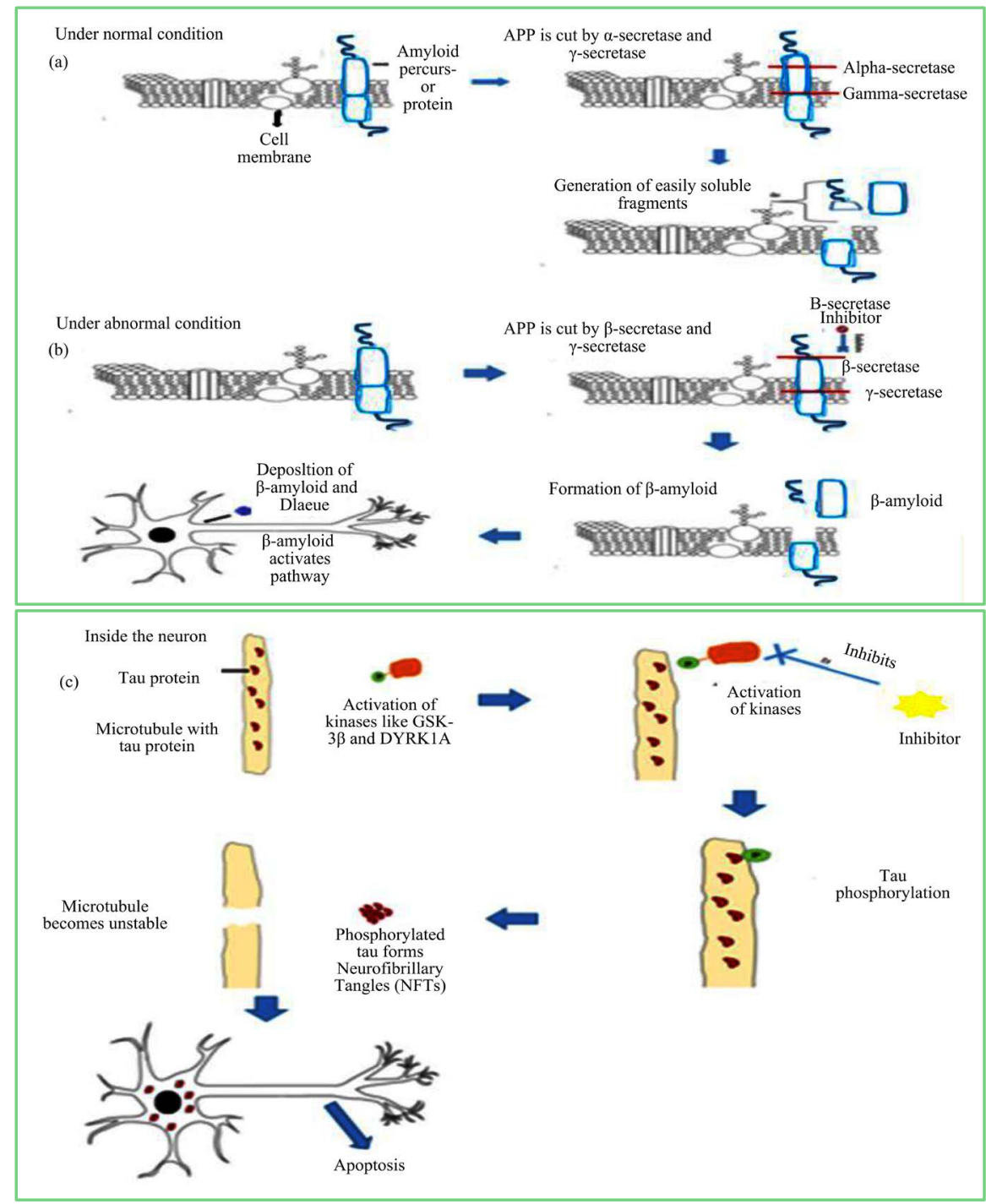

Figure 3. The underlying mechanism of Alzheimer's Disease (AD). (a) Figure a shows the processing of APP by $\alpha$-secretase and $\gamma$-secretase and production of easily degradable fragments; (b) Figure b shows the abnormal cleavage of APP by $\beta$-secretase and $\gamma$-secretase and production of $\beta$-amyloid plaques; (c) Figure $\mathrm{c}$ shows the mechanisms activated by amyloid plaques inside the neuron. The amyloid plaques cause the formation of NFTs and disruption of microtubules which eventually leads to the apoptosis of the neuron.

\section{3. $\beta$-Secretase (Receptor) and Dihydrospiro[Dibenzo[a,d][7]Annulene-5,4'-Imidazol] (Ligand)}

The pathway of $\beta$-secretase enzyme involves the abnormal proteolytic processing of APP. The cleavage of the APP protein by $\beta$-secretase leads to the formation of $\beta$-amyloid (A $\beta$ ) plaques [34].

The formation of $\mathrm{A} \beta$ is decided by the activities of three enzymes: $\alpha$-, $\beta$ - and $\gamma$-secretases. The APP protein can be cleaved by two major pathways: nonamyloidogenic pathway and amyloidogenic pathway. In non-amyloidogenic pathway, the transmembrane portion of APP protein is cleaved sequentially by 
$\alpha$ - and $\gamma$-secretases. These cleavages don't lead to the formation of $\mathrm{A} \beta$. Since $\alpha$-secretase cleave within the $\mathrm{A} \beta$ region, the $\mathrm{A} \beta$ formation never occurs [26]. However, in the amyloidogenic pathway, the abnormal cleavage of APP is carried out sequentially by $\beta$ - and $\gamma$-secretases and the $\beta$-secretase cuts the APP protein at a site 99 amino acids away from the C-terminus, leaving the C-terminal portion of the protein in the membrane, called C99. This newly generated $\mathrm{C} 99$ fragment contains the first amino acid of the $\mathrm{A} \beta$ plaque, at the newly generated N-terminus. Then $\gamma$-secretase cuts the C99 between 38th and 43th amino acids and liberates the $\mathrm{A} \beta$ peptides, which later aggregate together with other $\mathrm{A} \beta$ peptides and form plaques. This $\mathrm{A} \beta$ plaque formation is one of the main reasons behind the $\mathrm{AD}$ onset (Figure 3) [35].

One of the current approaches to treat $\mathrm{AD}$ is the use of $\beta$-secretase inhibitors that can inhibit the activity of $\beta$-secretase [36]. In Silico, studies have already been conducted against $\beta$-secretase (PDB ID: 2OHM) using

1,3-disubstituted-1H-pyrazol-5-ols as the inhibitors [33]. Another compound, named dihydrospiro[dibenzo[a,d][7]annulene-5,4'-imidazol], has been patented as an potent inhibitor of $\beta$-secretase [13]. In our study, docking study was performed with dihydrospiro[dibenzo[a,d][7]annulene-5,4'-imidazol] (PubChem CID: 24983268) against $\beta$-secretase (PDB ID: 2OHM).

\subsection{DYRK1A Enzyme (Receptor) and Harmine, Harmol, 1-Methyl-4-Phenylpyridinium (Ligands)}

Abnormal phosphorylation of tau protein is one of the main reasons of $\mathrm{AD}$ development [37]. Many enzymes are responsible for such type of phosphorylation, for example, glycogen synthase kinase 3 (GSK-3), cyclin-dependent kinase 5 (CDK-5), cAMP-dependent protein kinase A etc. The DYRK1A (dual specificity tyrosine $(\mathrm{Y})$-phosphorylation-regulated kinase $1 \mathrm{~A}$ ) is a recently discovered enzyme that is also responsible for the abnormal phosphorylation of tau protein. This enzyme is expressed from the DYRK1A gene of $21^{\text {st }}$ chromosome. This enzyme exhibits dual specificity. First, the enzyme autophosphorylates itself on the tyrosine 321 residue for activation and then phosphorylation of the target protein occurs [38].

The abnormally phosphorylated tau acquires the shape of paired helical filaments (PHFs) and forms NFTs that are insoluble and appear to be accumulated as tangled mass in the brain (Figure 3) [28].

Current treatment focusing on DYRK1A enzyme uses various inhibitors that can bind to the DYRK1A enzyme and inhibit its activity. Some of the inhibitors are: harmine, harmol, 1-methyl-4-phenylpyridinium etc. [14]. Docking was performed using the inhibitors: harmine (PubChem CID: 5280953), harmol (PubChem CID: 68094), 1-methyl-4-phenylpyridinium (PubChem CID: 39484) against the DYRK1A enzyme (PDB ID: 2VX3).

\subsection{In Silico Docking Study and ADME/T-Test}

Due to the advancements of various computer softwares, it is now possible to 
simulate the biological environment with the aid of various softwares without even using the original biological environment. Molecular docking is a technique that places a possible ligand molecule in the binding site of a suspected target protein. Molecular docking acts on algorithms that determine the potential interactions between macromolecules like protein-protein interactions, protein-drug interactions etc. These algorithms examine the orientational and conformational degrees of freedom of ligand molecules within the binding pocket of the target molecules and generate scores to select the best possible pose of the ligands for ranking them in correct order [39] [40].

$\mathrm{ADME} / \mathrm{T}$ test determines the $\mathrm{ADME} / \mathrm{T}$ properties of means a drug or candidate molecule. The ADME/T test determines how a candidate drug molecule may be absorbed, distributed, metabolized and excreted as well as its toxicological properties. ADME/T-test is one of the prerequisites for a potential candidate molecule to become a successful drug [41] [42].

In this experiment, eight drug molecules: memantine, hymenialdisine, tideglusib, kenpaullone, dihydrospiro[dibenzo[a,d][7]annulene-5,4'-imidazol], harmine, harmol and 1-methyl-4-phenylpyridinium, which have already been patented or developed in trials, have been used to dock against four proteins: NMDAR, glycogen synthase kinase-3 (GSK-3), $\beta$-secretase and dual specificity tyrosine (Y)-phosphorylation-regulated kinase $1 \mathrm{~A}$ (DYRK1A), respectively, to study their potential interaction in a search for the best possible drug compound.

\section{Materials and Methods}

Ligand preparation, Grid generation and Glide docking, 2D representations of the best pose interactions between the ligands and their respective receptors were obtained using Maestro-Schrödinger Suite 2015-1 and the 3D representations of the best pose interactions between the ligands and their respective receptors were visualized using Discovery Studio Visualizer [43] [44]. The 2D structures of ligands were downloaded from PubChem in SDF format (https://pubchem.ncbi.nlm.nih.gov/) and the receptors were downloaded from Protein Data Bank (http://www.rcsb.org/).

\subsection{Protein Preparation}

Three dimensional structures of NMDAR (PDB ID:3OEM), GSK-3 $\beta$ (PDB ID:1Q5K), $\beta$-secretase (PDB ID:2OHM) and DYRK1A (PDB ID:2VX3) were downloaded (sequentially) in PDB format from the Protein Data Bank (http://www.rcsb.org/) online server (Figure 4). The proteins were then prepared and refined using the Protein Preparation Wizard in Maestro Schrödinger Suite 2015-1. Bond orders were assigned and hydrogens were added to heavy atoms. Selenomethionines were converted to methionines as well as all the waters were deleted. Finally, the structure was optimized and then minimized using force field OPLS_2005. Minimization was done setting the maximum heavy 
atom RMSD (root-mean-square-deviation) to $30 \AA$ and any remaining water less than $3 \mathrm{H}$ bonds to non water was again deleted during the minimization step.

\subsection{Ligand Preparation}

The 2D conformations of memantine (PubChem CID: 4054), hymenialdisine (PubChem ID: 11313622), tideglusib (PubChem CID: 135413546), kenpaullone (PubChem CID: 3820), dihydrospiro[dibenzo[a,d][7]annulene-5,4'-imidazol] (PubChem CID: 24983268), harmine (PubChem CID: 5280953), harmol (PubChem CID: 68094) and 1-methyl-4-phenylpyridinium (PubChem CID: 39484) were downloaded (sequentially) from PubChem

(http://www.pubchem.ncbi.nlm.nih.gov/) (Figure 5). These structures were then prepared using the LigPrep function of Maestro Schrödinger Suite 2015-1. Minimized 3D structures of ligands were generated using Epik2.2 and within $\mathrm{pH}$ $7.0 \pm$ 2.0. Minimization was again carried out using OPLS_2005 force field which generated 32 possible stereoisomers.

\subsection{Receptor Grid Generation}

Grid usually confines the active site to shortened specific area of the receptor protein for the ligand to dock specifically. In Glide, a grid was generated using default van der Waals radius scaling factor 1.0 and charge cutoff 0.25 which was then subjected to OPLS_2005 force field. A cubic box was generated around the active site (reference ligand active site). Then the grid box volume was adjusted to $15 \times 15 \times 15$ for docking test.
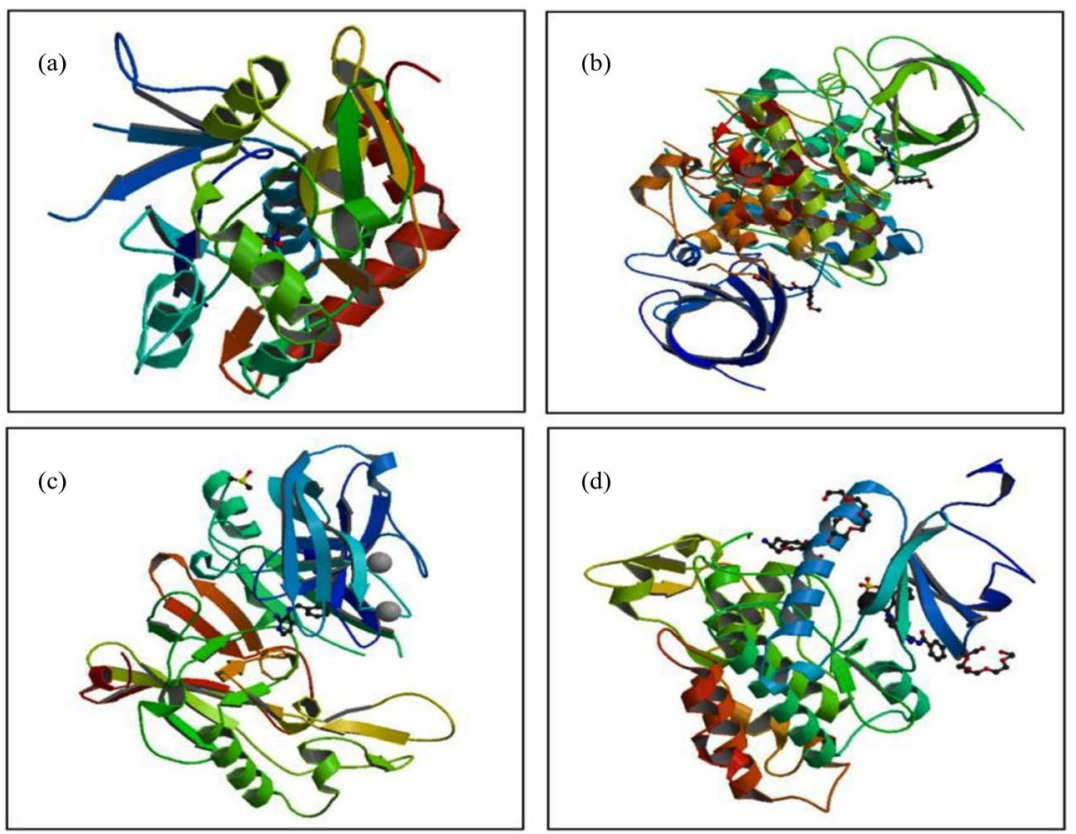

Figure 4. 3D representation of the target receptors. (a) 3D view of a N-Methyl-DAspartate Receptor (GluN2D) (PDB ID: 3OEM); (b) 3D view of GSK-3 $\beta$ (PDB ID: 1Q5K); (c) 3D representation of $\beta$-secretase (PDB Id: 2OHM); (d) 3D representation of DYRK1A (PDB ID: 2VX3). 


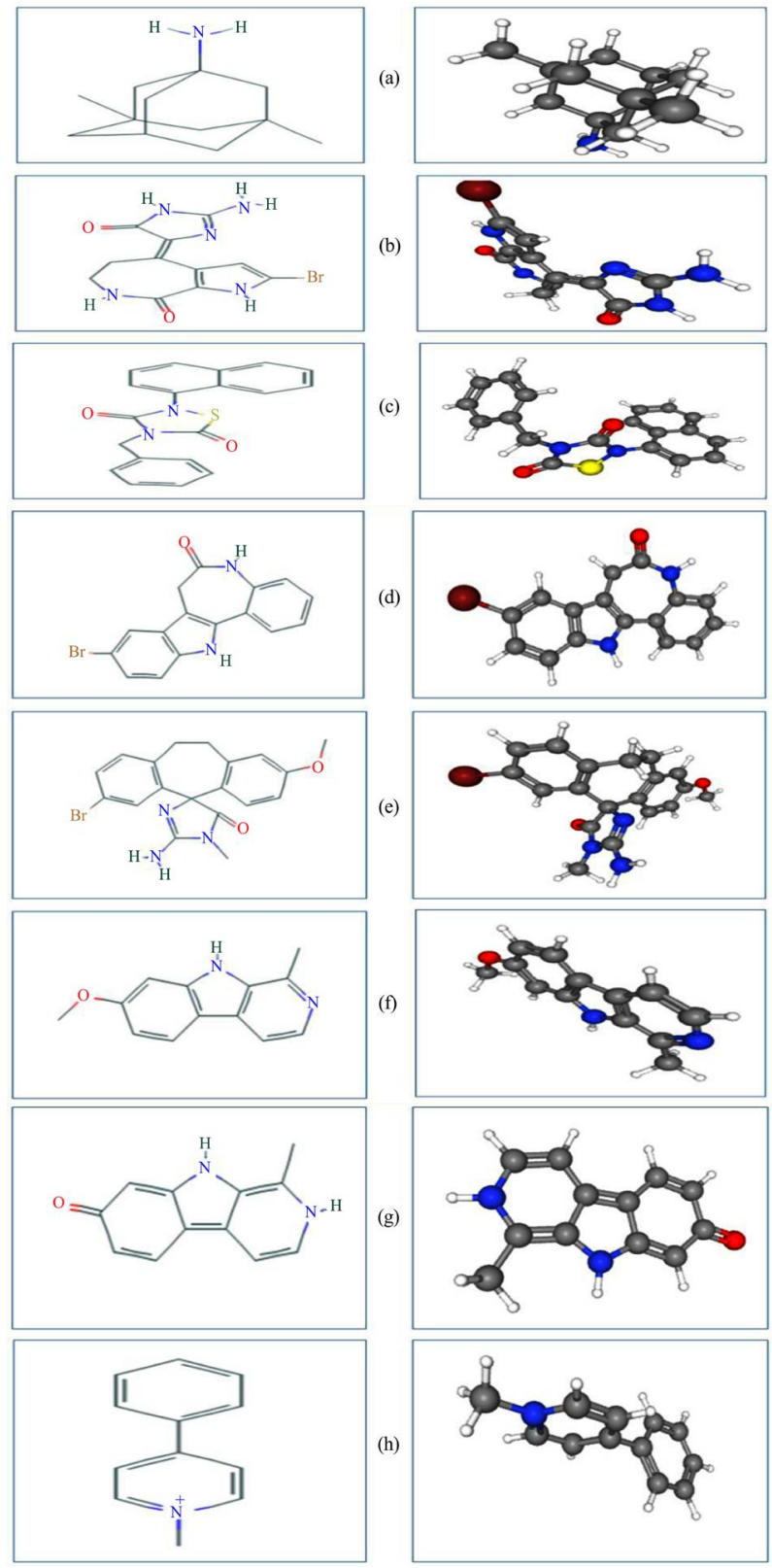

Figure 5. 2D (left) and 3D (right) representation of all the selected ligand molecules. (a) Memantine; (b) Hymenialdisine; (c) Tideglusib; (d) Kenpaullone; (e) Dihydrospiro[dibenzo[a,d][7]annulene-5,4'-imidazol]; (f) Harmine; (g) Harmol and (h) 1-Methyl-4-Phenylpyridinium.

\subsection{Glide Standard Precision (SP) Ligand Docking}

SP adaptable glide docking was carried out using Glide in Maestro Schrödinger Suite 2015-1. The Van der Waals radius scaling factor and charge cutoff were set to 0.80 and 0.15 respectively for all the ligand molecules. Final score was assigned according to the pose of docked ligand within the active site of the receptor. The ligand with the lowest glide docking score was considered as the best ligand. The docking results are listed in Table 1. After successful docking, the 2D representations of the best pose interactions between the ligands and their re- 
spective receptors were generated using Maestro-Schrödinger Suite 2015-1 (Figure 6). The 3D representations of the best pose interactions between the ligands and their respective receptors were obtained using Discovery Studio Visualizer (Figure 7).
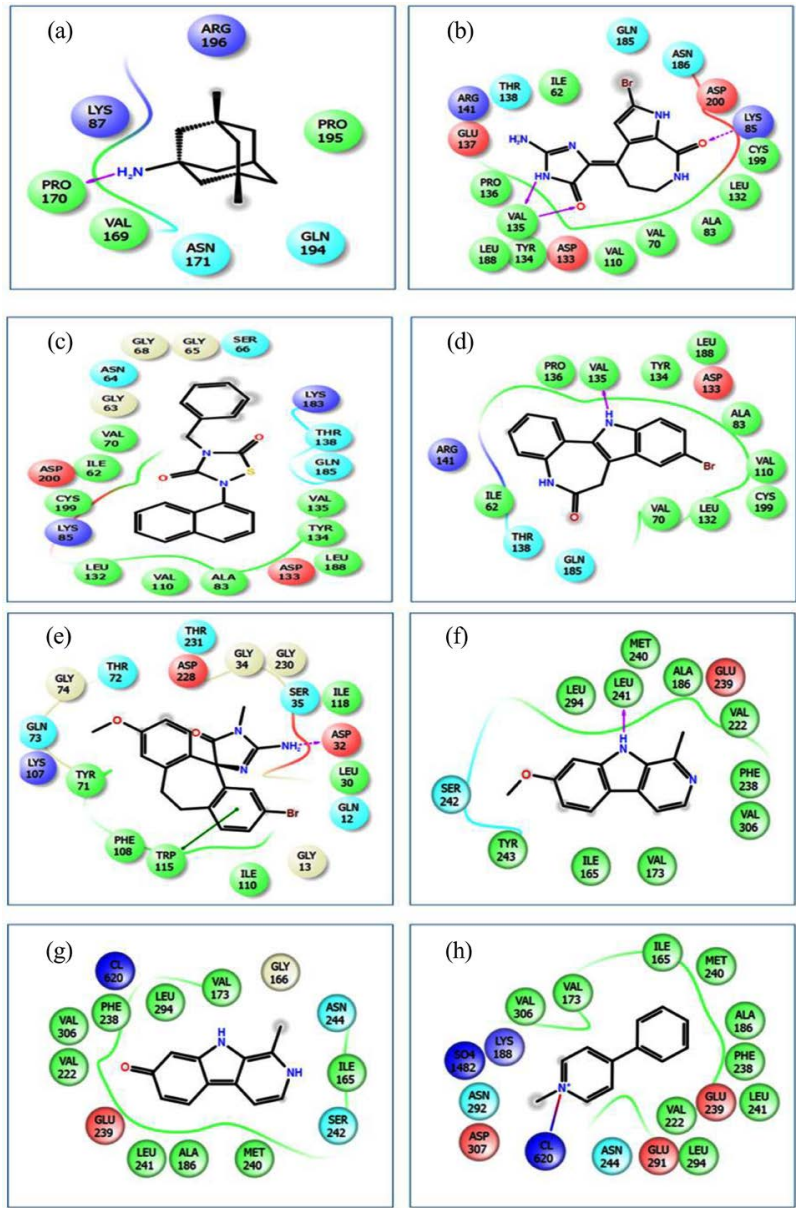

Figure 6. 2D representations of the best pose interactions between the ligands and their respective receptors. (a) interaction between Memantine and NMDAR; (b) interaction between Hymenialdisine and GSK-3 $\beta$; (c) interaction between Tideglusib and GSK-3 $\beta$; (d) interaction between Kenpaullone and GSK-3 $\beta$; (e) interaction between Dihydrospiro[dibenzo[a,d][7]annulene-5,4'-imidazol] and $\beta$-secretase; (f) interaction between Harmine and DYRK1A; (g) interaction between Harmol and DYRK1A; $(\mathrm{h})$ interaction between 1-Methyl-4-Phenylpyridinium and DYRK1A. Colored spheres indicates the type of residue in the target: Red-Negatively charged (Asp, Glu), Blue-Polar (Ser, Thr, Gln, Asn), Green-Hydrophobic (Ala, Val, Leu, Ile, Tyr, Trp, Phe, Met, Cys, Pro), Light Purple-Basic (Lys, Arg), Gray-Water molecules, Darker gray-metal atom, Light Yellow-Glycine, Deep Purple-Unspecified molecules and the Grayish circles represent Solvent exposure. Interactions are shown as colored lines-Solid pink lines with arrow-H-bond in target (backbone), Dotted pink lines with arrow-H-bond between receptor and ligand (sidechain), Solid pink lines without arrow-Metal co-ordination, Green line-Pi-Pi stacking interaction, Green dotted lines-Distances, Partially blue and red colored lines-Salt bridges. Ligands exposed to solvent are represented by grey sphere. The colored lines show the protein pocket for the ligand according to the nearest atom. Interruptions of the lines indicate the opening of the pocket. 

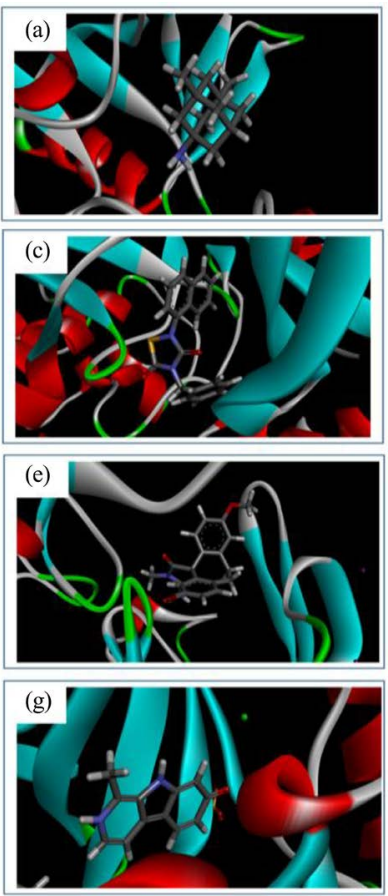
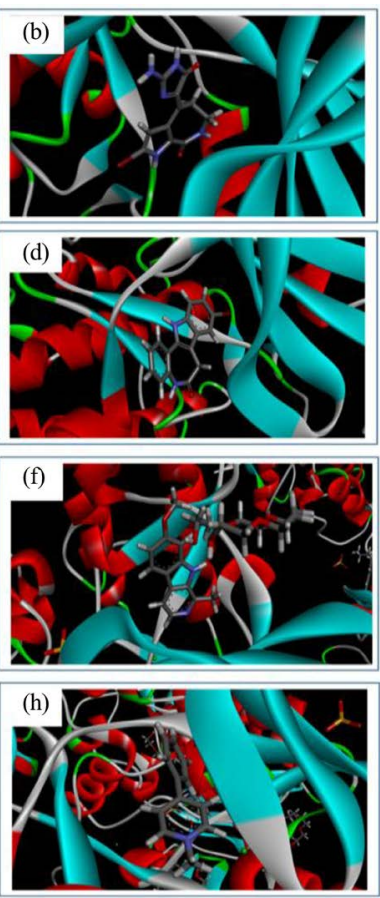

Figure 7. 3D representations of the best pose interactions between the ligands and their respective receptors. The proteins are represented in Solid ribbon model and the ligands are represented in Stick model. (a) Interaction between Memantine and NMDAR; (b) Interaction between Hymenialdisine and GSK-3 $\beta$; (c) Interaction between Tideglusib and GSK-3 $\beta$; (d) Interaction between Kenpaullone and GSK-3 $\beta$; (e) Interaction between Dihydrospiro[dibenzo[a,d][7]annulene-5,4'-imidazol] and $\beta$-secretase; (f) Interaction between Harmine and DYRK1A; (g) Interaction between Harmol and DYRK1A; (h) Interaction between 1-Methyl-4-Phenylpyridinium and DYRK1A.

Table 1. Results of molecular docking between the selected ligands and receptors.

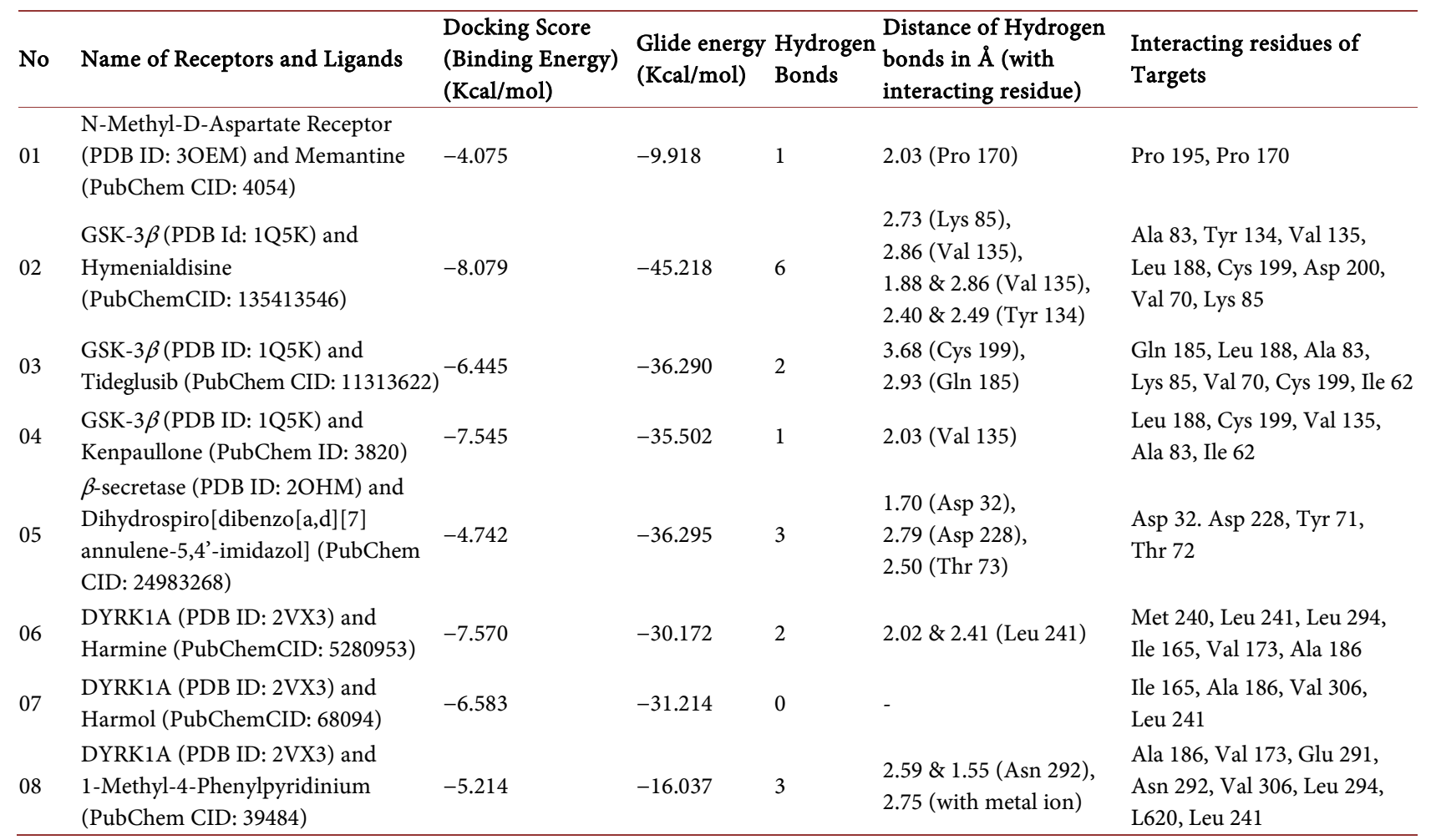




\subsection{Ligand Based Drug Likeness Property and ADME/Toxicity Prediction}

The molecular structures of every ligands were analyzed using SWISSADME server (http://www.swissadme.ch/) to confirm whether they obey Lipinki's rule of five or not, along with some other properties. Various physicochemical properties of ligand molecules were calculated using OSIRIS Property Explorer (https://www.organic-chemistry.org/prog/peo/). The drug likeness properties of the selected ligand molecules were analyzed using SWISSADME server (http://www.swissadme.ch/) as well as the OSIRIS Property Explorer (https://www.organic-chemistry.org/prog/peo/). The results of drug likeness property analysis are summarized in Table 2 [45]. The ADME/T for each of the ligand molecules was carried out using an online-based server ADMET-SAR (http://lmmd.ecust.edu.cn/admetsar1/predict/) to predict their various pharmacokinetic and pharmacodynamic properties including blood brain barrier permeability, human abdominal adsorption, Caco-2 permeability, Cytochrome $\mathrm{P}$ (CYP) inhibitory capability, carcinogenicity, mutagenicity etc. The result of ADME/T for all the ligand molecules is depicted in Table 3.

\section{Result}

\subsection{Binding Energy}

All the selected ligand molecules were docked successfully against NMDAR, GSK-3 $\beta, \beta$-secretase and DYRK1A.

Memantine generated docking score (binding energy) of $-4.075 \mathrm{Kcal} / \mathrm{mol}$ and glide energy of $-9.918 \mathrm{Kcal} / \mathrm{mol}$, when docked against NMDAR. Memantine formed 1 hydrogen bond with proline 170 residue of NMDAR and the distance was $2.03 \AA$ (Table 1 and Figure 8).

Hymenialdisine generated docking score of $-8.079 \mathrm{Kcal} / \mathrm{mol}$ and glide energy of $-45.218 \mathrm{Kcal} / \mathrm{mol}$, when docked against GSK-3 $\beta$. Hymenialdisine formed 6 hydrogen bonds with lysine 85, valine 135 (formed 2 hydrogen bonds), tyrosine 134 ( 2 bonds) and aspartic acid 200 residues of GSK-3 $\beta$ and the distances were 2.73, 2.86, 1.88, 2.86, 2.49 and 2.40 Å, respectively (Table 1 and Figure 8).

Tideglusib generated docking score of $-6.445 \mathrm{Kcal} / \mathrm{mol}$ and glide energy of $-36.290 \mathrm{Kcal} / \mathrm{mol}$, when docked against GSK-3 $\beta$ and generated 2 hydrogen bonds with the target protein GSK-3 $\beta$ (Table 1 and Figure 8 ).

Kenpaullone generated docking score of $-7.545 \mathrm{Kcal} / \mathrm{mol}$ and glide energy of $-35.502 \mathrm{Kcal} / \mathrm{mol}$, when docked against GSK-3 $\beta$. Kenpaullone formed 1 hydrogen bond with valine 135 of GSK-3 $\beta$ and the distance was $2.03 \AA$ (Table 1 and Figure 8).

Dihydrospiro[dibenzo[a,d][7]annulene-5,4'-imidazol] generated docking score of $-4.742 \mathrm{Kcal} / \mathrm{mol}$ and glide energy of $-36.295 \mathrm{Kcal} / \mathrm{mol}$, when docked against $\beta$-secretase. Dihydrospiro[dibenzo[a,d][7]annulene-5,4'-imidazol] formed 3 hydrogen bonds with aspartic acid 32, threonine 73 and aspartic acid 228 residues of $\beta$-secretase and the distances were 1.70, 2.50 and $2.79 \AA$, respectively (Table 1 and Figure 8). 
Table 2. Druglikeness properties of selected ligand molecules. The drug likeness properties of the ligand molecules were determined using SWISSADME server (http://www.swissadme.ch/) and OSIRIS Property Explorer

(https://www.organic-chemistry.org/prog/peo/).

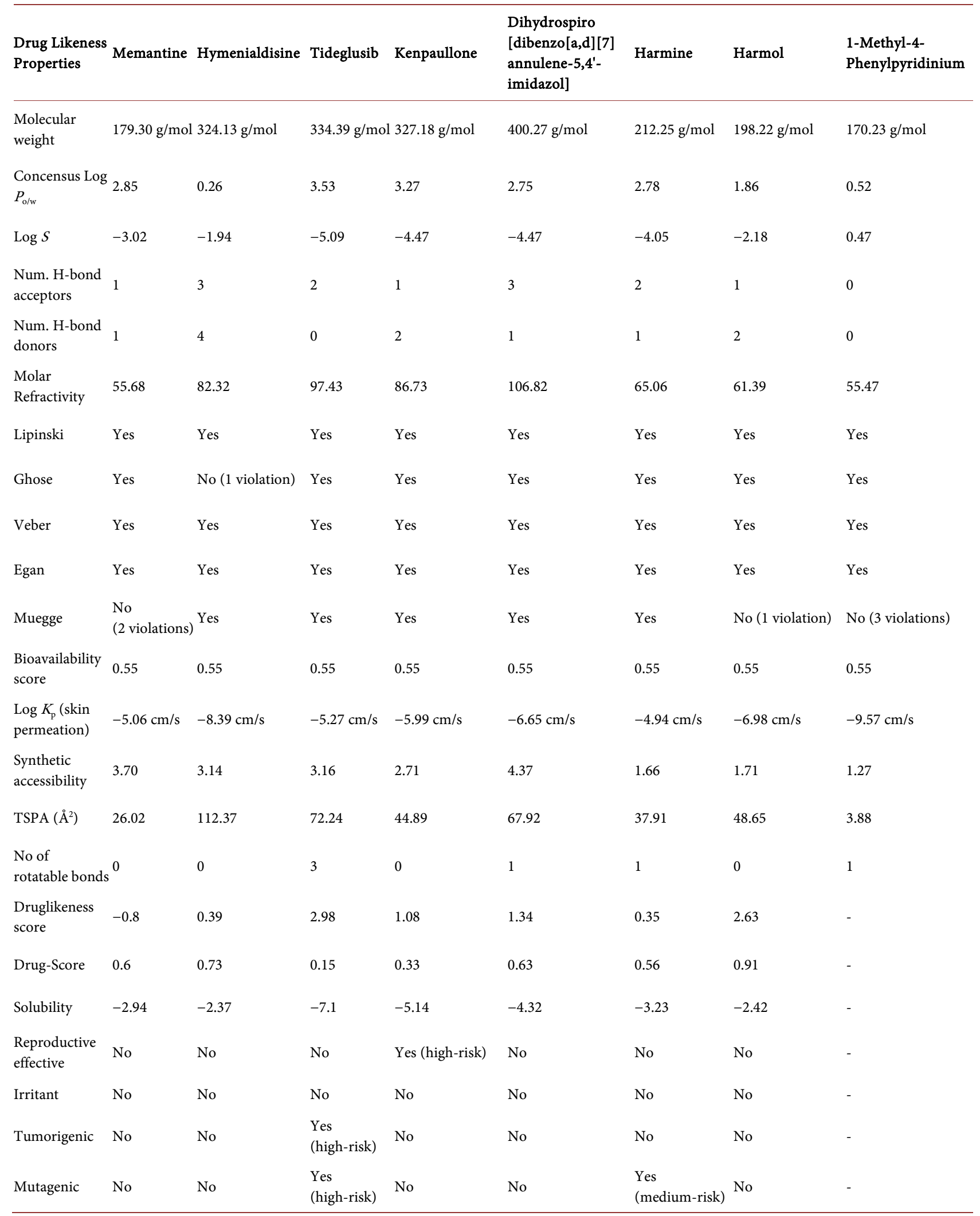


Table 3. Results of ADME/T-test of selected ligands. The ADME/T-tests for the ligand molecules were carried out using an online based server ADMET-SAR (http://lmmd.ecust.edu.cn/admetsar1/predict/).

\begin{tabular}{|c|c|c|c|c|c|c|c|c|}
\hline Properties & Memantine & Hymenialdisin & Tideglusib & Kenpaullone & $\begin{array}{l}\text { Dihydrospiro } \\
\text { [dibenzo[a,d] } \\
\text { [7] annulene } \\
\text {-5,4'-imidazol] }\end{array}$ & Harmine & Harmol & $\begin{array}{l}\text { 1-Methyl-4-Phe } \\
\text { nylpyridinium }\end{array}$ \\
\hline $\begin{array}{l}\text { Blood-Brain } \\
\text { Barrier }\end{array}$ & $\mathrm{BBB}+$ & $\mathrm{BBB}+$ & $\mathrm{BBB}+$ & $\mathrm{BBB}+$ & $\mathrm{BBB}+$ & $\mathrm{BBB}+$ & $\mathrm{BBB}+$ & $\mathrm{BBB}+$ \\
\hline $\begin{array}{l}\text { Human } \\
\text { Intestinal } \\
\text { Absorption }\end{array}$ & HIA+ & $\mathrm{HIA}+$ & HIA+ & HIA+ & HIA+ & HIA+ & HIA+ & HIA+ \\
\hline $\begin{array}{l}\text { Caco-2 } \\
\text { Permeability }\end{array}$ & Caco2+ & Caco2- & Caco2- & Caco2- & Caco2- & Caco2- & Caco2- & Caco2+ \\
\hline $\begin{array}{l}\text { P-glycoprotein } \\
\text { Substrate }\end{array}$ & Non-substrate & Substrate & Non-substrate & Non-substrate & Substrate & Non-substrate & Substrate & Non-substrate \\
\hline $\begin{array}{l}\text { P-glycoprotein } \\
\text { Inhibitor }\end{array}$ & Non-inhibitor & Non-inhibitor & Non-inhibitor & Non-inhibitor & Non-inhibitor & Non-inhibitor & Non-inhibitor & Non-inhibitor \\
\hline $\begin{array}{l}\text { Renal Organic } \\
\text { Cation } \\
\text { Transporter }\end{array}$ & Non-inhibitor & Non-inhibitor & Non-inhibitor & Non-inhibitor & Non-inhibitor & Non-inhibitor & Non-inhibitor & Non-inhibitor \\
\hline $\begin{array}{l}\text { Subcellular } \\
\text { localization }\end{array}$ & Lysosome & Mitochondria & Mitochondria & Mitochondria & Lysosome & Mitochondria & Mitochondria & Mitochondria \\
\hline $\begin{array}{l}\text { CYP450 2C9 } \\
\text { Substrate }\end{array}$ & Non-substrate & Non-substrate & Non-substrate & Non-substrate & Non-substrate & Non-substrate & Non-substrate & Non-substrate \\
\hline $\begin{array}{l}\text { CYP450 2D6 } \\
\text { Substrate }\end{array}$ & Non-substrate & Non-substrate & Non-substrate & Non-substrate & Non-substrate & Non-substrate & Non-substrate & Non-substrate \\
\hline $\begin{array}{l}\text { CYP450 3A4 } \\
\text { Substrate }\end{array}$ & Non-substrate & Substrate & Non-substrate & Substrate & Substrate & Non-substrate & Non-substrate & Non-substrate \\
\hline $\begin{array}{l}\text { CYP450 1A2 } \\
\text { Inhibitor }\end{array}$ & Non-inhibitor & Inhibitor & Non-inhibitor & Inhibitor & Inhibitor & Inhibitor & Inhibitor & Non-inhibitor \\
\hline $\begin{array}{l}\text { CYP450 2C9 } \\
\text { Inhibitor }\end{array}$ & Non-inhibitor & Non-inhibitor & Inhibitor & Non-inhibitor & Non-inhibitor & Non-inhibitor & Non-inhibitor & Non-inhibitor \\
\hline $\begin{array}{l}\text { CYP450 2D6 } \\
\text { Inhibitor }\end{array}$ & Non-inhibitor & Non-inhibitor & Non-inhibitor & Inhibitor & Non-inhibitor & Inhibitor & Inhibitor & Non-inhibitor \\
\hline $\begin{array}{l}\text { CYP450 2C19 } \\
\text { Inhibitor }\end{array}$ & Non-inhibitor & Non-inhibitor & Inhibitor & Non-inhibitor & Non-inhibitor & Non-inhibitor & Non-inhibitor & Non-inhibitor \\
\hline $\begin{array}{l}\text { CYP450 3A4 } \\
\text { Inhibitor }\end{array}$ & Non-inhibitor & Non-inhibitor & Non-inhibitor & Inhibitor & Non-inhibitor & Inhibitor & Non-inhibitor & Non-inhibitor \\
\hline & Low CYP & Low CYP & High CYP & High CYP & Low CYP & High CYP & Low CYP & High CYP \\
\hline Promiscuity & $\begin{array}{l}\text { Inhibitory } \\
\text { Promiscuity }\end{array}$ & $\begin{array}{l}\text { Inhibitory } \\
\text { Promiscuity }\end{array}$ & $\begin{array}{l}\text { Inhibitory } \\
\text { Promiscuity }\end{array}$ & $\begin{array}{l}\text { Inhibitory } \\
\text { Promiscuity }\end{array}$ & $\begin{array}{l}\text { Inhibitory } \\
\text { Promiscuity }\end{array}$ & $\begin{array}{l}\text { Inhibitory } \\
\text { Promiscuity }\end{array}$ & $\begin{array}{l}\text { Inhibitory } \\
\text { Promiscuity }\end{array}$ & $\begin{array}{l}\text { Inhibitory } \\
\text { Promiscuity }\end{array}$ \\
\hline AMES Toxicity & \multicolumn{6}{|c|}{ Non-AMES toxicNon-AMES toxicNon-AMES toxicNon-AMES toxicNon-AMES toxicAMES-toxic } & AMES-toxic & Non-AMES toxic \\
\hline Carcinogens & \multicolumn{8}{|c|}{ Non-carcinogensNon-carcinogensNon-carcinogensNon-carcinogensNon-carcinogensNon-carcinogensNon-carcinogensNon-carcinogens } \\
\hline Biodegradation & $\begin{array}{l}\text { Not ready } \\
\text { biodegradable }\end{array}$ & $\begin{array}{l}\text { Not ready } \\
\text { biodegradable }\end{array}$ & $\begin{array}{l}\text { Not ready } \\
\text { biodegradable }\end{array}$ & $\begin{array}{l}\text { Not ready } \\
\text { biodegradable }\end{array}$ & $\begin{array}{l}\text { Not ready } \\
\text { biodegradable }\end{array}$ & $\begin{array}{l}\text { Not ready } \\
\text { biodegradable }\end{array}$ & $\begin{array}{l}\text { Not ready } \\
\text { biodegradable }\end{array}$ & $\begin{array}{l}\text { Not ready } \\
\text { biodegradable }\end{array}$ \\
\hline $\begin{array}{l}\text { Acute Oral } \\
\text { Toxicity }\end{array}$ & III & III & III & III & III & III & III & III \\
\hline
\end{tabular}



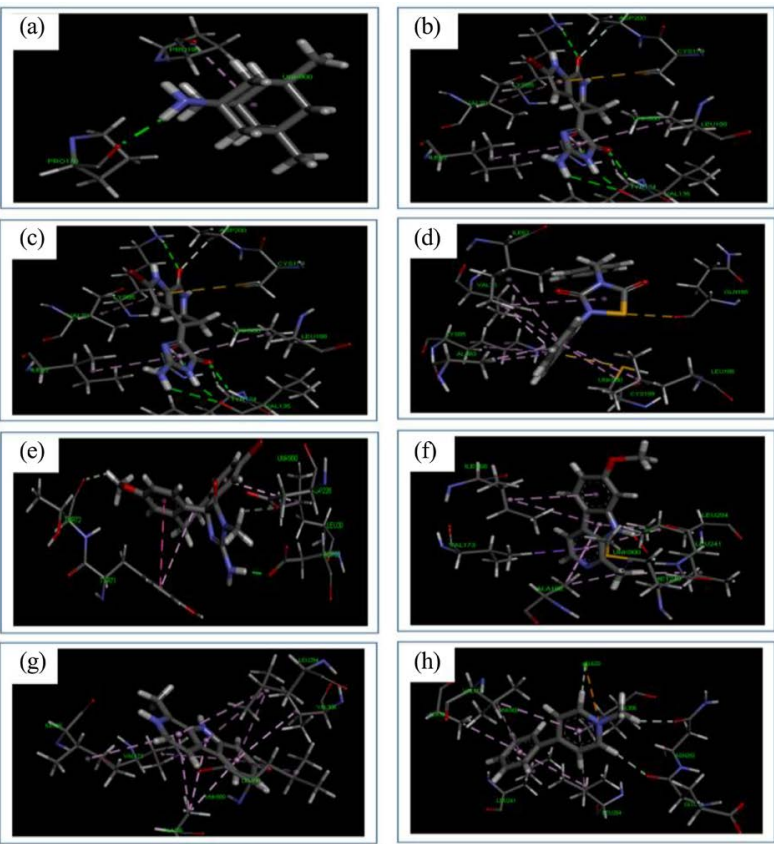

Figure 8. Figure showing the various types of bonds and amino acids that take part in the interaction between the selected ligands and respective receptors. Interacting amino acid residues of target molecule are labeled in the diagram and dotted lines depict interaction between ligand and receptor. Green dotted lines-Conventional bond, Light pink-Alkyl/ Pi-Alkyl interactions, Yellow-Pi-Sulfur/Sulphur-X interaction, Deep pink-Pi-Pi stacked bond, Orange-Charge-Charge interaction, Purple-Pi-Sigma interaction, Red-DonorDonor interaction. (a) interaction between Memantine and NMDAR; (b) interaction between Hymenialdisine and GSK-3 $\beta$; (c) interaction between Tideglusib and GSK-3 $\beta$; (d) interaction between Kenpaullone and GSK-3 $\beta$; (e) interaction between Dihydrospiro[dibenzo[a,d][7]annulene-5,4'-imidazol] and $\beta$-secretase; (f) interaction between Harmine and DYRK1A; (g) interaction between Harmol and DYRK1A; $(\mathrm{h})$ interaction between 1-Methyl-4-Phenylpyridinium and DYRK1A.

Harmine generated docking score of $-7.570 \mathrm{Kcal} / \mathrm{mol}$ and glide energy of $-30.172 \mathrm{Kcal} / \mathrm{mol}$, when docked against DYRK1A. Harmine formed 2 hydrogen bonds with leucine 241 residue of DYRK1A and the distances were 2.02 and 2.41 Å (Table 1 and Figure 8).

Harmol generated docking score of $-6.583 \mathrm{Kcal} / \mathrm{mol}$ and glide energy of $-31.214 \mathrm{Kcal} / \mathrm{mol}$, when docked against DYRK1A. However, harmol did not generate any hydrogen bond with the target protein DYRK1A (Table 1 and Figure 8).

1-methyl-4-phenylpyridinium generated docking score of $-5.214 \mathrm{Kcal} / \mathrm{mol}$ and glide energy of $-16.037 \mathrm{Kcal} / \mathrm{mol}$, when docked against DYRK1A and generated 3 hydrogen bonds with the target protein DYRK1A, unlike harmol (Table 1 and Figure 8).

\subsection{Druglikeness Property}

Lipinski's rule of five demonstrates that the acceptable ranges of the best drug molecule for all the five parameters are: molecular weight: $\leq 500$, number of hy- 
drogen bond donors: $\leq 5$, number of hydrogen bond acceptors: $\leq 10$, lipophilicity (expressed as $\log \mathrm{P}$ ): $\leq 5$, molar refractivity from 40 to 130 [46]. All the ligand molecules followed the Lipinski's rule of five without any violation. The results are listed in Table 2.

None of the molecules violated the Veber and Egan rules. Only hymenialdisine violated the Ghose filter factor. However, memantine, harmol and 1-methyl-4-phenylpyridinium violated the Muegge rule of druglikeness properties. All the molecules showed similar bioavaibility score of 0.55 .

Tideglusib showed the lowest LogS value of -5.09 , whereas, 1-methyl-4-phenylpyridinium had the highest LogS value of 0.47 . Kenpaullone and dihydrospiro[dibenzo[a,d][7]annulene-5,4'-imidazol] showed similar LogS values, -4.47 . Hymenialdisine and harmol showed slightly similar LogS values of -1.94 and -2.18 , respectively. Memantine and harmine had LogS values of -3.02 and -4.05 , respectively.

Memantine, kenpaullone and harmol had 1 hydrogen bond acceptor each. Both tideglusib and harmine had 2 hydrogen bond acceptors. Moreover, both hymenialdisine and dihydrospiro[dibenzo[a,d][7]annulene-5,4'-imidazol] had 3 hydrogen bond acceptors. However, 1-methyl-4-phenylpyridinium didn't show any hydrogen bond acceptor. Memantine,

dihydrospiro[dibenzo[a,d][7]annulene-5,4'-imidazol] and harmine had 1 hydrogen bond donor each, whereas kenpaullone and harmol had 2 and hymenialdisine had 4 hydrogen bond donors. However, tideglusib and 1-methyl-4-phenylpyridinium didn't have any hydrogen bond donor.

Dihydrospiro[dibenzo[a,d][7]annulene-5,4'-imidazol] showed the highest molar refractivity of 106.82 and 1-methyl-4-phenylpyridinium had the lowest score of 55.47, although memantine had also very close score to 1-methyl-4-phenylpyridinium (55.68). Harmine and harmol had quite similar scores (65.06 and 61.39, respectively). Hymenialdisine, tideglusib and kenpaullone had scores of $82.32,97.43$ and 86.73 , respectively.

Hymenialdisine possessed the largest topological polar surface area (TPSA) $\left(112.37 \AA^{2}\right)$ and 1-methyl-4-phenylpyridinium had the lowest area of $3.88 \AA^{2}$. Tideglusib and dihydrospiro[dibenzo[a,d][7] annulene-5,4'-imidazol] had almost similar scores of $72.24 \AA^{2}$ and $67.92 \AA^{2}$, respectively. Memantine had quite low score of 26.02. The results showed by the rest of the molecules were: 44.89 (kenpaullone), 37.91 (harmine) and 48.65 (harmol). Tideglusib exhibited the highest druglikeness score of 2.98 and the lowest solubility score (-7.1), however, its drug score was very low (0.15) and it showed very high tumorigenic and mutagenic activity. Tideglusib had no effect on reproductive system and irritation. Harmol should be the best molecule in this regard since it showed good druglikeness score of 2.63 and very good drug score of 0.91 , second highest solubility score $(-2.42)$ and it did not exhibit any of the deleterious effects. Kenpaullone showed druglikeness score of 1.08 , solubility score of -5.14 and drug score of 0.33 , however, its reproductive effectivity was quite high, although it didn't have any irritant, tumorigenic and 
mutagenic properties. Dihydrospiro[dibenzo[a,d][7]annulene-5,4'-imidazol] also showed relatively good druglikeness score (1.34) and drug score (0.63) as well as moderate solubility $(-4.32)$ and it had no reproductive effectiveness or irritant, tumorigenic and mutagenic properties. Other molecules, memantine, hymenialdisine, harmine had druglikeness scores of $-0.8,0.39,0.35$, respectively and drug scores of 0.6, 0.73 and 0.56, respectively. Memantine and hymenialdisine showed no harmful effect, however, harmine was quite mutagenic. However, the druglikeness score, drug score, solubility score, reproductive effectiveness, irritation properties, tumorigenic and mutagenic properties of 1-methyl-4-phenylpyridinium are not determined yet.

\subsection{ADME/T-Test}

The results of ADME/T test of selected ligand molecules are listed in Table 3. All the ligand molecules showed the ability to cross the Blood-Brain Barrier (BBB) and gave positive results in human intestinal absorption (HIA). Only memantine and 1-methyl-4-phenylpyridinium showed Caco-2 permeability. All the molecules were proved to be P-glycoprotein Inhibitors.

All the molecules were non-substrate of CYP450 2C9 and CYP450 2D6. However, hymenialdisine, kenpaullone and dihydrospiro[dibenzo[a,d][7] annulene-5,4'-imidazol] were substrates of CYP450 3A4, whereas other molecules were non-substrates. Memantine, tideglusib and 1-methyl-4-phenylpyridinium were non-inhibitors of CYP450 1A2, however, the other ligand molecules were inhibitors. Only tideglusib showed inhibition of CYP450 2C9. Kenpaullone, harmine and harmol were the inhibitors of CYP450 2D6 and only tideglusib was the CYP450 2C19 inhibitor. Kenpaullone and harmine were the inhibitors of CYP450 3A4. Tideglusibe, kenpaullone, harmine and 1-methyl-4-phenylpyridinium showed high CYP inhibitory promiscuity. Others showed low CYP inhibitory promiscuity.

Only harmine and harmol showed AMES-toxicity. Though all the ligand molecules were non-carcinogenic, all of them were not readily biodegradable and all of them showed level-III oral acute toxicity.

\section{Discussion}

Molecular docking demonstrates the best possible pose of a ligand molecule within the binding site of the receptor molecule and calculates a score of binding energy. This score is also known as the "docking score". The lower the binding energy, the higher the affinity of binding and vice versa [47]. Hymenialdisine exhibited the strongest binding with its target GSK- $3 \beta$ with the lowest binding energy of $-8.079 \mathrm{Kcal} / \mathrm{mol}$ and as a result interacted with the most number of amino acids (8) in the target molecule backbone. On the other hand, memantine bound with NMDAR with the highest binding energy $(-4.075 \mathrm{Kcal} / \mathrm{mol})$ and interacted with the least number of amino acids (2) inside the binding pocket of NMDAR. Second lowest docking score was given by harmine $(-7.570 \mathrm{Kcal} / \mathrm{mol})$ 
when docked against DYRK1A and interacted with six amino acids in the target molecule backbone. Kenpaullone exhibited docking score of $-7.545 \mathrm{Kcal} / \mathrm{mol}$ when docked against GSK-3 $\beta$ and interacted with five amino acids in the target molecule backbone.

The specificity of the interaction between ligands and their receptors increases with the number of hydrogen bond. Therefore, hydrogen bond contributes to the molecular recognition of ligands and receptors and their strength of interaction [48]. Hymenialdisine formed the most number of hydrogen bonds (6) with its receptor protein. Memantine and kenpaullone formed hydrogen bond, each, dihydrospiro[dibenzo[a,d][7]annulene-5,4'-imidazol] and harmine formed 3 hydrogen bonds, each, with their respective targets. Tideglusib, harmine fromed 2 hydrogen bonds with their targets. However, harmol didn't form any hydrogen bond.

The main objective of estimating the druglikeness property is to fructify the drug discovery and development process. The permeability of the drug molecule through the biological barrier is influenced by the molecular weight and topological polar surface area (TPSA). The higher the molecular weight and TPSA, the lower the permeability is and vice versa. Lipophilicity is expressed as LogP values and conferred as the logarithm of partition coefficient of the candidate molecule in organic and aqueous phase. Lipophilicity influences the absorption of the drug molecule in the body. Lower $\log \mathrm{P}$ associates with higher absorption and vice versa. LogS value affects the solubility of the target drug molecule and the lowest value is considered as the best value. The number of hydrogen bond donors and acceptors beyond the acceptable range affects the ability of a drug molecule to cross cell membrane. The number of rotatable bonds also influences the oral bioavailability of a candidate drug molecule and it is assumed to be within 10 as the acceptable range. Moreover, the Lipinski's rule of five demonstrates that a successful drug molecule should have properties within the acceptable range of the five Lipinski's rules [46] [49] [50]. All the ligand molecules in this experiment followed standard rule of druglikeness property (Lipinski's rule of five).

ADME/T-tests examine the pharmacological and pharmacodynamic properties of a candidate drug molecule inside a biological system. Therefore, it is a crucial determinant of the success of a drug discovery approach. BBB is the most crucial element for those drugs that target primarily the brain cells. Oral delivery system is the most commonly used route of drug administration. Therefore, it would be appreciable that the drug is highly absorbed in intestinal tissue. Since P-glycoprotein in the cell membrane facilitates the transport of many drugs, therefore, its inhibition may affect the drug transport. In vitro study of drug permeability test utilizes Caco- 2 cell line and its permeability reflects that the drug is easily absorbed in the intestine. Orally absorbed drugs travel through the blood circulation and deposit back to liver where it is degraded by group of enzymes of Cytochrome P450 family and excreted as bile or urine. Therefore, inhi- 
bition of any of enzymes of this family affects the biodegradation of the drug molecule [42] [51]. The results of the ADME/T-test are listed in Table 3.

Taking all the parameters into consideration, memantine performed quite well in ADME/T-test (NMDAR target). Hymenialdisine exhibited the best results than other molecules that interacted with GSK-3 $\beta$. The other two molecules, tideglusib and kenpaullone showed almost similar results. Dihydrospiro[dibenzo[a,d][7]annulene-5,4'-imidazol] uses $\beta$-secretase as its target and it showed fair, although not satisfactory results. Among the molecules that target DYRK1A, 1-methyl-4-phenylpyridinium exhibited fairly good results and the other two molecules, harmine and harmol showed almost similar results.

According to the Ghose filter, to qualify as a drug molecule, the compound should have $\log \mathrm{P}$ value between -0.4 and 5.6, molecular weight between 160 and 480 , molar refractivity between 40 and 130 and the total number of atoms between 20 and 70 [52]. Among the ligands, only hymenialdisine violated the Ghose filter factor. According to the Veber rule, the oral bioavailability of a candidate drug depends on two factors: 10 or fewer numbers of rotatable bonds and the polar surface are which should be equal to or less than $140 \AA^{2}$ [53]. No ligand violated the Veber rule. According to the Egan rule, the absorption of a drug molecule depends on two factors: the polar surface area (PSA) and AlogP98 (the logarithm of partition co-efficient between n-octanol and water) [54]. All the ligands obeyed the Egan rule. Moreover, according to the Muegge rule, for a drug like chemical matter or compound to become a drug, it has to pass a pharmacophore point filter developed by the scientists [55]. Memantine, harmol and 1-methyl-4-phenylpyridinium violated the Muegge rules of druglikeness properties. The list of molecules that obey or violate these above mentioned rules are given in Table 2.

The synthetic accessibility (SA) score estimates how easily a target compound can be synthesized. The score 1 represents very easy to synthesize and the score 10 represents very hard to synthesize [56]. 1-methyl-4-phenylpyridinium showed the lowest SA score of 1.27 , therefore, it can be very easily synthesized. Dihydrospiro[dibenzo[a,d][7]annulene-5,4'-imidazol] gave the highest score of 4.37, as a result, it is the most difficult compound among the selected ligands to be synthesized. Hymenialdisine and tideglusib showed almost similar scores, although these results were not very good (3.14 and 3.16, respectively). Harmine and harmol exhibited quite good results, which indicate that they are quite easy to synthesize (1.66 and 1.71, respectively). Moreover, memantine and kenpaullone exhibited scores of 3.70 and 2.71, respectively, which are not satisfactory. The synthetic accessibility scores are listed in Table 2 . The bioavailability score gives the insight of permeability and bioavailability properties of a compound [57]. All the ligands showed similar bioavailability score of 0.55.

All the ligand molecules have been docked successfully against their target proteins. This indicates that all of them can inhibit their target proteins. Memantine showed the best result among all the ligands in the ADME/T test, how- 
ever, the binding energy with NMDAR was the highest among all the ligands $(-4.075 \mathrm{kcal} / \mathrm{mol})$ and the druglikess properties were moderate. Hymenialdisine exhibited the lowest binding energy $(-8.079 \mathrm{Kcal} / \mathrm{mol})$ when docked against GSK- $3 \beta$, however, its druglikness properties and ADME/T-test results were quite good. Though, tideglusib exhibited quite good result in docking with GSK-3 $\beta$ $(-6.445 \mathrm{Kcal} / \mathrm{mol})$, it lacked good druglikeness properties and ADME/T-test results. Kenpaullone showed quite satisfactory docking score of $-7.545 \mathrm{Kcal} / \mathrm{mol}$, however, its druglikeness properties and $\mathrm{ADME} / \mathrm{T}$-test results were not satisfactory. Among all the molecules that use GSK- $3 \beta$ as target, hymenialdisine exhibited the best results. The docking results of dihydrospiro[dibenzo[a,d][7]annulene-5,4'imidazol] were not good when docked against $\beta$-secretase $(-4.742 \mathrm{Kcal} / \mathrm{mol})$. It performed quite well in druglikeness property experiments but showed moderate type of results in ADME/T-test. Among all the molecules that target DYRK1A, harmol showed the best results considering he docking results (score $-6.583 \mathrm{Kcal} / \mathrm{mol}$ ), druglikeness properties and ADME/T-test results. In many aspects, although harmine and harmol exhibited almost similar results, however, they showed significant differences in some of their properties. For example, harmine obeyed the Mugge rule, whereas harmol didn't. Moreover, harmine showed mutagenic (medium-risk) properties, on the contrary, harmol didn't exhibit such toxicity. They also differed significantly from each other in their LogS values (harmine had -4.05 and harmol had -2.18 ), the druglikeness scores (harmine had score of 0.35 and harmol had 2.63) and drug scores (harmine had score of 0.56 and harmol had score of 0.91 ). These differences indicate that harmol should be the drug of choice over harmine. Moreover, the results of harmine and 1-methyl-4-phenylpyridinium were good in some aspects, although not so satisfactory considering all the terms to be called the best possible drug molecule among the selected DYRK1A inhibitors.

\section{Conclusion}

Eight drug molecules were investigated to find out the best possible drug against their respective targets and thus the best possible treatment to cure AD. Many drugs are already available in the market and many more are still in pre-clinical and clinical trials. This experiment was focused to analyze eight drug molecules to select the best ones which can be directed against various specific targets (four) in Alzheimer's Disease. Findings of this experiment suggest that memantine can be administered if the treatment of $\mathrm{AD}$ focuses on inhibiting the NMDAR activity. Moreover, hymenialdisine should be administered if the treatment targets GSK-3 $\beta$. Since dihydrospiro[dibenzo[a,d][7]annulene-5,4'imidazol] exhibited fairly good results, it can also be used in AD treatment targeting $\beta$-secretase. And if the target is the DYRK1A enzyme, then harmol should be administered as the best possible drug molecule. Finally, these four ligand molecules could be considered as the best drugs among all the selected drug molecules in this experiment depending on their performance for treating AD. 
However, other molecules could also be investigated as they also performed well in docking experiment. Hopefully, the results of this study should help the researchers to identify the best treatment process to treat $\mathrm{AD}$.

\section{Acknowledgements}

Authors are thankful to Swift Integrity Computational Lab, Dhaka, Bangladesh, a virtual platform of young researchers, for providing the tools.

\section{Conflicts of Interest}

The authors declare no conflicts of interest regarding the publication of this paper.

\section{References}

[1] Suh, W.H., Suslick, K.S. and Suh, Y.H. (2005) Therapeutic Agents for Alzheimer's Disease. Current Medicinal Chemistry-Central Nervous System Agents, 5, 259-269. https://doi.org/10.2174/156801505774913035

[2] Ferri, C.P., Prince, M., Brayne, C., Brodaty, H., Fratiglioni, L., Ganguli, M., et al. (2005) Global Prevalence of Dementia: A Delphi Consensus Study. The Lancet, 366, 2112-2117. https://doi.org/10.1016/S0140-6736(05)67889-0

[3] Merriam, A.E., Aronson, M.K., Gaston, P., Wey, S.L. and Katz, I. (1988) The Psychiatric Symptoms of Alzheimer's Disease. Journal of the American Geriatrics Society, 36, 7-22. https://doi.org/10.1111/j.1532-5415.1988.tb03427.x

[4] Nordberg, A. and Svensson, A.L. (1998) Cholinesterase Inhibitors in the Treatment of Alzheimer's Disease. Drug Safety, 19, 465-480. https://doi.org/10.2165/00002018-199819060-00004

[5] Hardy, J.A. and Higgins, G.A. (1992) Alzheimer's Disease: The Amyloid Cascade Hypothesis. Science, 256, 184-186. https://doi.org/10.1126/science.1566067

[6] Markesbery, W.R. (1997) Oxidative Stress Hypothesis in Alzheimer's Disease. Free Radical Biology and Medicine, 23, 134-147. https://doi.org/10.1016/S0891-5849(96)00629-6

[7] Francis, P.T., Palmer, A.M., Snape, M. and Wilcock, G.K. (1999) The Cholinergic Hypothesis of Alzheimer's Disease: A Review of Progress. Journal of Neurology, Neurosurgery \& Psychiatry, 66, 137-147. https://doi.org/10.1136/jnnp.66.2.137

[8] Galimberti, D. and Scarpini, E. (2011) Disease-Modifying Treatments for Alzheimer's Disease. Therapeutic Advances in Neurological Disorders, 4, 203-216. https://doi.org/10.1177/1756285611404470

[9] Danysz, W. and Parsons, C.G. (2003) The NMDA Receptor Antagonist Memantine as a Symptomatological and Neuroprotective Treatment for Alzheimer's Disease: Preclinical Evidence. International Journal of Geriatric Psychiatry, 18, S23-S32. https://doi.org/10.1002/gps.938

[10] Martinez, A., Castro, A., Dorronsoro, I. and Alonso, M. (2002) Glycogen Synthase Kinase 3 (GSK-3) Inhibitors as New Promising Drugs for Diabetes, Neurodegeneration, Cancer, and Inflammation. Medicinal Research Reviews, 22, 373-384. https://doi.org/10.1002/med.10011

[11] del Ser, T., Steinwachs, K.C., Gertz, H.J., Andres, M.V., Gomez-Carrillo, B., Medina, M., et al. (2013) Treatment of Alzheimer's Disease with the GSK-3 Inhibitor Tideglusib: A Pilot Study. Journal of Alzheimer's Disease, 33, 205-215. 
https://doi.org/10.3233/JAD-2012-120805

[12] Leost, M., Schultz, C., Link, A., Wu, Y.Z., Biernat, J., Mandelkow, E.M., Bibb, J.A., Snyder, G.L., Greengard, P., Zaharevitz, D.W. and Gussio, R. (2000) Paullones Are Potent Inhibitors of Glycogen Synthase Kinase- $3 \beta$ and Cyclin-Dependent Kinase 5/p25. European Journal of Biochemistry, 267, 5983-5994.

https://doi.org/10.1046/j.1432-1327.2000.01673.x

[13] Quagliato, D.A., Andrae, P.M., Fan, Y. and Wyeth, L.L.C. (2009) Dihydrospiro [Dibenzo[a, d][7]Annulene-5,4'-imidazol] Compounds for the Inhibition of Beta-Secretase. U.S. Patent No. 7582667. https://doi.org/10.2210/pdb4dus/pdb

[14] Smith, B., Medda, F., Gokhale, V., Dunckley, T. and Hulme, C. (2012) Recent Advances in the Design, Synthesis, and Biological Evaluation of Selective DYRK1A Inhibitors: A New Avenue for a Disease Modifying Treatment of Alzheimer's? ACS Chemical Neuroscience, 3, 857-872. https://doi.org/10.1021/cn300094k

[15] Riedel, G., Platt, B. and Micheau, J. (2003) Glutamate Receptor Function in Learning and Memory. Behavioural Brain Research, 140, 1-47.

https://doi.org/10.1016/S0166-4328(02)00272-3

[16] Collingridge, G.L., Olsen, R.W., Peters, J. and Spedding, M. (2009) A Nomenclature for Ligand-Gated Ion Channels. Neuropharmacology, 56, 2-5. https://doi.org/10.1016/j.neuropharm.2008.06.063

[17] Wang, R. and Reddy, P.H. (2017) Role of Glutamate and NMDA Receptors in Alzheimer's Disease. Journal of Alzheimer's Disease, 57, 1041-1048. https://doi.org/10.3233/JAD-160763

[18] Choi, D.W. (1988) Glutamate Neurotoxicity and Diseases of the Nervous System. Neuron, 1, 623-634. https://doi.org/10.1016/0896-6273(88)90162-6

[19] Talantova, M., Sanz-Blasco, S., Zhang, X., Xia, P., Akhtar, M.W., Okamoto, S.I., et al. (2013) A $\beta$ Induces Astrocytic Glutamate Release, Extrasynaptic NMDA Receptor Activation, and Synaptic Loss. Proceedings of the National Academy of Sciences, 110, E2518-E2527. https://doi.org/10.1073/pnas.1511280112

[20] De Felice, F.G., Velasco, P.T., Lambert, M.P., Viola, K., Fernandez, S.J., Ferreira, S.T., et al. (2007) A $\beta$ Oligomers Induce Neuronal Oxidative Stress through an N-methyl-D-aspartate Receptor-Dependent Mechanism That Is Blocked by the Alzheimer Drug Memantine. Journal of Biological Chemistry, 282, 11590-11601. https://doi.org/10.1074/jbc.M607483200

[21] Vance, K.M., Simorowski, N., Traynelis, S.F. and Furukawa, H. (2011) Ligand-Specific Deactivation Time Course of GluN1/GluN2D NMDA Receptors. Nature Communications, 2, Article No. 294. https://doi.org/10.1038/ncomms1295

[22] Plattner, F., Angelo, M. and Giese, K.P. (2006) The Roles of Cyclin-Dependent Kinase 5 and Glycogen Synthase Kinase 3 in Tau Hyperphosphorylation. Journal of Biological Chemistry, 281, 25457-25465. https://doi.org/10.1074/jbc.M603469200

[23] Mattson, M.P. (2004) Pathways towards and Away from Alzheimer's Disease. Nature, 430, 631-639. https://doi.org/10.1038/nature02621

[24] Hardy, J. and Selkoe, D.J. (2002) The Amyloid Hypothesis of Alzheimer's Disease: Progress and Problems on the Road to Therapeutics. Science, 297, 353-356. https://doi.org/10.1126/science.1072994

[25] Roberds, S.L., Anderson, J., Basi, G., Bienkowski, M.J., Branstetter, D.G., Chen, K.S., et al. (2001) BACE Knockout Mice Are Healthy Despite Lacking the Primary $\beta$-Secretase Activity in Brain: Implications for Alzheimer's Disease Therapeutics. Human Molecular Genetics, 10, 1317-1324. https://doi.org/10.1093/hmg/10.12.1317

[26] Kojro, E. and Fahrenholz, F. (2005) The Non-Amyloidogenic Pathway: Structure 
and Function of $\alpha$-Secretases. Sub-Cellular Biochemistry, 38, 105-127. https://doi.org/10.1007/0-387-23226-5_5

[27] Reddy, P.H. and Beal, M.F. (2008) Amyloid Beta, Mitochondrial Dysfunction and Synaptic Damage: Implications for Cognitive Decline in Aging and Alzheimer's Disease. Trends in Molecular Medicine, 14, 45-53.

https://doi.org/10.1016/j.molmed.2007.12.002

[28] Augustinack, J.C., Schneider, A., Mandelkow, E.M. and Hyman, B.T. (2002) Specific Tau Phosphorylation Sites Correlate with Severity of Neuronal Cytopathology in Alzheimer's Disease. Acta Neuropathologica, 103, 26-35. https://doi.org/10.1007/s004010100423

[29] Eldar-Finkelman, H. (2002) Glycogen Synthase Kinase 3: An Emerging Therapeutic Target. Trends in Molecular Medicine, 8, 126-132. https://doi.org/10.1016/S1471-4914(01)02266-3

[30] Hanger, D.P., Byers, H.L., Wray, S., Leung, K.Y., Saxton, M.J., Seereeram, A., et al. (2007) Novel Phosphorylation Sites in Tau from Alzheimer Brain Support a Role for Casein Kinase 1 in Disease Pathogenesis. Journal of Biological Chemistry, 282, 23645-23654. https://doi.org/10.1074/jbc.M703269200

[31] Otth, C., Concha, I.I., Arendt, T., Stieler, J., Schliebs, R., González-Billault, C. and Maccioni, R.B. (2002) A $\beta$ PP Induces cdk5-Dependent Tau Hyperphosphorylation in Transgenic Mice Tg2576. Journal of Alzheimer's Disease, 4, 417-430. https://doi.org/10.3233/JAD-2002-4508

[32] Llorens-Marítin, M., Jurado, J., Hernández, F. and Ávila, J. (2014) GSK-3 $\beta$, a Pivotal Kinase in Alzheimer Disease. Frontiers in Molecular Neuroscience, 7, 46. https://doi.org/10.3389/fnmol.2014.00046

[33] Sarojini, B.K., Vidyagayatri, M., Darshanraj, C.G., Bharath, B.R. and Manjunatha, H. (2010) DPPH Scavenging Assay of Novel 1, 3-disubstituted-1H-pyrazol-5-ols and Their in Silico Studies on Some Proteins Involved in Alzheimer's Disease Signaling Cascade. Letters in Drug Design \& Discovery, 7, 214-224. https://doi.org/10.2174/157018010790596588

[34] Li, R., Lindholm, K., Yang, L.B., Yue, X., Citron, M., Yan, R., et al. (2004) Amyloid $\beta$ Peptide Load Is Correlated with Increased $\beta$-Secretase Activity in Sporadic Alzheimer's Disease Patients. Proceedings of the National Academy of Sciences, 101, 3632-3637. https://doi.org/10.1073/pnas.0205689101

[35] LaFerla, F.M., Green, K.N. and Oddo, S. (2007) Intracellular Amyloid- $\beta$ in Alzheimer's Disease. Nature Reviews Neuroscience, 8, 499-509. https://doi.org/10.1038/nrn2168

[36] Yan, R. and Vassar, R. (2014) Targeting the $\beta$ Secretase BACE1 for Alzheimer's Disease Therapy. The Lancet Neurology, 13, 319-329. https://doi.org/10.1016/S1474-4422(13)70276-X

[37] Bramblett, G.T., Goedert, M., Jakes, R., Merrick, S.E., Trojanowski, J.Q. and Lee, V.M. (1993) Abnormal Tau Phosphorylation at Ser396 in Alzheimer's Disease Recapitulates Development and Contributes to Reduced Microtubule Binding. Neuron, 10, 1089-1099. https://doi.org/10.1016/0896-6273(93)90057-X

[38] Ryoo, S.R., Jeong, H.K., Radnaabazar, C., Yoo, J.J., Cho, H.J., Lee, H.W., Kim, I.S., et al. (2007) DYRK1A-Mediated Hyperphosphorylation of Tau A Functional Link between Down Syndrome and Alzheimer Disease. Journal of Biological Chemistry, 282, 34850-34857. https://doi.org/10.1074/jbc.M707358200

[39] Kolb, P. and Irwin, J.J. (2009) Docking Screens: Right for the Right Reasons? Current Topics in Medicinal Chemistry, 9, 755-770. 
https://doi.org/10.2174/156802609789207091

[40] Levine, D., Facello, M., Hallstrom, P., Reeder, G., Walenz, B. and Stevens, F. (1997) Stalk: An Interactive System for Virtual Molecular Docking. IEEE Computational Science and Engineering, 4, 55-65. https://doi.org/10.1109/99.609834

[41] Selick, H.E., Beresford, A.P. and Tarbit, M.H. (2002) The Emerging Importance of Predictive ADME Simulation in Drug Discovery. Drug Discovery Today, 7, 109-116. https://doi.org/10.1016/S1359-6446(01)02100-6

[42] Li, A.P. (2001) Screening for Human ADME/Tox Drug Properties in Drug Discovery. Drug Discovery Today, 6, 357-366. https://doi.org/10.1016/S1359-6446(01)01712-3

[43] (2015) Schrödinger Release 2015-1: Maestro. Schrödinger, LLC, New York. https://www.schrodinger.com/maestro

[44] Visualizer, D.S. (2017) Release 4.1. Accelrys Inc., San Diego. https://www.3dsbiovia.com

[45] Lipinski, C.A., Lombardo, F., Dominy, B.W. and Feeney, P.J. (1997) Experimental and Computational Approaches to Estimate Solubility and Permeability in Drug Discovery and Development Settings. Advanced Drug Delivery Reviews, 23, 3-25. https://doi.org/10.1016/S0169-409X(96)00423-1

[46] Lipinski, C.A. (2004) Lead- and Drug-Like Compounds: The Rule-of-Five Revolution. Drug Discovery Today: Technologies, 1, 337-341. https://doi.org/10.1016/j.ddtec.2004.11.007

[47] Yuriev, E. and Ramsland, P.A. (2013) Latest Developments in Molecular Docking: 2010-2011 in Review. Journal of Molecular Recognition, 26, 215-239. https://doi.org/10.1002/jmr.2266

[48] Hubbard, R.E. and Kamran Haider, M. (2001) Hydrogen Bonds in Proteins: Role and Strength. https://doi.org/10.1002/9780470015902.a0003011.pub2

[49] Sander, T. (2001) OSIRIS Property Explorer. Organic Chemistry Portal. https://www.organic-chemistry.org/prog/peo

[50] Pollastri, M.P. (2010) Overview on the Rule of Five. Current Protocols in Pharmacology, 49, 9-12. https://doi.org/10.1002/0471141755.ph0912s49

[51] Guengerich, F.P. (1999) Cytochrome P-450 3A4: Regulation and Role in Drug Metabolism. Annual Review of Pharmacology and Toxicology, 39, 1-7. https://doi.org/10.1146/annurev.pharmtox.39.1.1

[52] Ghose, A.K., Viswanadhan, V.N. and Wendoloski, J.J. (1999) A Knowledge-Based Approach in Designing Combinatorial or Medicinal Chemistry Libraries for Drug Discovery. 1. A Qualitative and Quantitative Characterization of Known Drug Databases. Journal of Combinatorial Chemistry, 1, 55-68. https://doi.org/10.1021/cc9800071

[53] Veber, D.F., Johnson, S.R., Cheng, H.Y., Smith, B.R., Ward, K.W. and Kopple, K.D. (2002) Molecular Properties That Influence the Oral Bioavailability of Drug Candidates. Journal of Medicinal Chemistry, 45, 2615-2623. https://doi.org/10.1021/jm020017n

[54] Egan, W.J., Merz, K.M. and Baldwin, J.J. (2000) Prediction of Drug Absorption Using Multivariate Statistics. Journal of Medicinal Chemistry, 43, 3867-3877. https://doi.org/10.1021/jm000292e

[55] Muegge, I., Heald, S.L. and Brittelli, D. (2001) Simple Selection Criteria for Drug-Like Chemical Matter. Journal of Medicinal Chemistry, 44, 1841-1846. https://doi.org/10.1021/jm015507e 
[56] Ertl, P. and Schuffenhauer, A. (2009) Estimation of Synthetic Accessibility Score of Drug-Like Molecules Based on Molecular Complexity and Fragment Contributions. Journal of Cheminformatics, 1, Article No. 8. https://doi.org/10.1186/1758-2946-1-8

[57] Martin, Y.C. (2005) A Bioavailability Score. Journal of Medicinal Chemistry, 48, 3164-3170. https://doi.org/10.1021/jm0492002 